\title{
A psicanálise é o que reintroduz o Nome do pai na consideração científica. 0 que isso significa nos primeiro e segundo ensinos de Lacan?
}

Psychoanalysis is what reintroduces the name-of-the-father to the scientific scope. What does that mean in Lacan's first and second teachings?

El psicoanálisis es el que reintroduce el nombre-del-padre en el campo de la ciencia. ¿Qué significa eso en la primera y en la segund a enseñanza de Lacan?

Rosa Guedes Lopes*

\begin{abstract}
Resumo
Para Lacan, a psicanálise reintroduz o Nome do pai na consideração científica. A ciência moderna trata a existência do homem como dedução do pensamento, não como obra de Deus ou da natureza. A psicanálise opera sobre esse sujeito. Entretanto, não o toma como sujeito sem qualidades como a ciência. $\mathrm{O}$ sujeito não resulta apenas de um cálculo nem se exaure no pensamento. A operação do recalque é paradoxal: produz um sujeito separado do seu valor fálico, fato decisivo para o pensamento científico porque considera o princípio de realidade, mas produz também o desejo inconsciente. Isso comprova que é impossível ao sujeito comparecer sem qualidades. $S_{1}-S_{2}$ não são significantes sem qualidades. Implicam o desejo inconsciente. Este texto demonstra o que significa reintroduzir o Nome do pai na consideração científica. Percorre as vias do progresso e as descontinuidades desse conceito na passagem do primeiro ao segundo ensino de Lacan, principalmente com o conceito de objeto $a$.
\end{abstract}

Palavras-chave: psicanálise; sujeito da ciência; Nome do pai; realidade psíquica; objeto $a$.

\begin{abstract}
In Lacan's view, psychoanalysis reintroduces the Name-of-the-Father to the scientific scope. Modern science treats man's existence as a deduction of thought, not as a work of God or Nature. This is the subject that psychoanalysis operates on. However, it does not consider it a subject deprived of qualities as science does. The subject is not reduced to the
\end{abstract}

Texto recebido em fevereiro de 2008 e aprovado para publicação em setembro de 2009.

Doutora e mestra em Teoria Psicanalítica/PPGTP/IP/UFRJ, professora da Faculdade de Psicologia/Unesa, membro da Associação Núcleo Sephora de Pesquisa sobre o moderno e o contemporâneo, aderente da Escola Brasileira de Psicanálise - Seção Rio de Janeiro - UFRJ, e-mail: rosa.guedes.lopes@globo.com. 
result of calculation, nor does wear itself out in thought. The operation of repression is paradoxical: it produces a subject separated from its phallic value, a decisive fact for scientific thought because it takes the reality principle into account, but it also produces unconscious desire. This proves that it is impossible for the subject to appear with no qualities. S1S2 are not signifiers without qualities. They imply unconscious desire. This text demonstrates what it means to reintroduce the Name-of-theFather to the scientific scope. It follows the paths of the progression and discontinuities of this concept in the passage from the first to the second of Lacan's teachings, especially with the concept of object $a$.

Key words: Psychoanalysis; Subject of science; Name-of-the-Father; Psychic reality; Object $a$.

\section{Resumen}

Para Lacan, el psicoanálisis reintroduce el Nombre-del-Padre en el razonamiento científico. La ciencia moderna trata de la existencia del hombre como una deducción del pensamiento, no como obra de Dios o de la Naturaleza. El psicoanálisis opera sobre ese sujeto. Sin embargo, no lo toma como un sujeto sin cualidades, como hace la ciencia. El sujeto no resulta solamente de un cálculo ni se limita al pensamiento. La operación de recalcadura es paradójica: produce un sujeto apartado de su valor fálico, hecho decisivo para el pensamiento científico porque considera el principio de la realidad, sin embargo, produce también el deseo inconsciente. Eso comprueba que es imposible que el sujeto comparezca sin cualidades. $S_{1}-S_{2}$ no son significantes sin cualidades. Implican el deseo inconsciente. El presente texto demuestra lo que significa reintroducir el Nombre-del-Padre en el campo del razonamiento científico. Recorre las vías del progreso y las discontinuidades de tal concepto del paso de la primera a la segunda enseñanza de Lacan, principalmente con el concepto del objeto $a$.

Palabras-clave: psicoanálisis, sujeto de la ciencia, Nombre-del-Padre, realidad psíquica, objeto $a$.

\section{Introdução}

psicanálise opera sobre o sujeito da ciência (Lacan, 1998, p. 873). O
advento da ciência moderna engendrou uma mudança discursiva no
mundo: tratar a existência do homem como dedução do pensamento e
não mais como fruto da vontade de Deus ou obra da natureza. O surgimento da
psicanálise dependeu dessa mudança. Ao formalizar o sujeito do inconsciente
freudiano como efeito da determinação do significante que o representa para
outro significante, Lacan conceituou o sujeito como transindividual, portanto 
"sem qualidades" (Milner, 1996). Se o objeto da psicanálise é sem qualidades, isso permite afirmar que a psicanálise participa do gesto da ciência. Porém ela não se ocupa apenas de extrair o par ordenado S1-S2, raiz da determinação subjetiva. A prática da psicanálise implica operar sobre o sujeito e, nesse ponto, ela se diferencia da ciência. O sujeito sobre o qual opera é encarnado em um corpo e não apenas o resultado de um cálculo. Sua existência não se exaure na atividade do pensamento como consciência de si. O inconsciente é o avesso da consciência de si. O desejo inconsciente, resultado do recalque, comprova que é impossível ao sujeito da ciência comparecer sem qualidades. A operação lógica do recalque tem um resultado paradoxal. Por um lado, produz um sujeito separado do valor fálico que ele tem para sua mãe. Esse fato é decisivo para o pensamento científico, pois o recalque limita a tendência do aparelho psíquico a realizar o desejo de forma alucinatória, levando-o a considerar o princípio de realidade. No entanto, essa mesma operação produz um resíduo: o desejo inconsciente. Como resto, o desejo se mantém sob a égide do princípio do prazer, mas seu funcionamento passa ao largo do princípio de realidade. É o que o estudo freudiano dos sonhos demonstra. O sujeito do inconsciente é o que subsiste recalcado sob o sujeito da ciência. Em consequência, S1-S2 não é uma equação composta por significantes sem qualidades, mas a expressão da relação do sujeito com o desejo inconsciente. Entre S1 e S2, circula o desejo.

Os mitos freudianos sobre o pai (Édipo, o pai da horda primitiva, e Moisés) enquadram a fantasia inconsciente unindo o desejo à lei. Concebem o gozo como impossível ao sujeito e o desejo como vontade de alcançar a exceção situada além do princípio do prazer. Eles reproduzem a posição subjetiva moderna: o mito de Édipo, por exemplo, mostra o sujeito dividido entre o saber e a verdade (Lacan, 1998, p. 870). Revelam o que o discurso da ciência recalca: o desejo de ser exceção. Portanto, o sujeito não corresponde ao homem universal idealizado pela ciência. Ele é necessariamente sexuado como homem ou mulher. Não se pode banir toda a ilusão do campo do conhecimento porque tudo que se refere ao sexo (a fantasia, o desejo, o inconsciente e o sintoma) se comporta como obstáculo a essa pretensão.

Lacan criou o conceito de Nome do pai com a pretensão de formalizar o mito edípico, lugar da realidade psíquica em Freud, porque considerava que o campo mítico não era suficiente para explicar a estrutura subjetiva nos moldes científicos. Ao conceituar o Nome do pai, Lacan dá um passo a mais que Freud. Passa da representação e dos mitos ao conceito e ao matema. Em seguida, identifica o conceito à estrutura e esta ao sujeito. Eleva o mito à dignidade de estrutura (Lacan, 1992) e, com esse movimento, retira da psicanálise o excesso de imaginário que poderia deixar abertos os caminhos 
que tornariam seu campo de conhecimento estruturalmente correlato, por exemplo, ao da alquimia. É nesse contexto que Lacan afirma que a tarefa da psicanálise é reintroduzir o Nome do pai na consideração científica (1998, p. 889). Este texto pretende demonstrar o que este axioma significa.

\section{Lacan e o estruturalismo}

O retorno de Lacan sobre a obra de Freud é marcado, desde o início, pela introdução do campo do simbólico como responsável pela constituição de "uma dimensão distinta da experiência analítica e uma ordem própria de existência" (Lacan, 1987, p. 44). Lévi-Strauss é a mais importante referência de Lacan nesse período. Ao desmontar a estrutura dos mitos, Lévi-Strauss (1982) mostrou que eles podem ser reduzidos a um número limitado de elementos articulados em uma combinatória responsável por regular as permutações possíveis. A estrutura dos mitos mostra que a interdição do incesto é a única regra universal e a que assegura o domínio da cultura sobre a natureza (Lévi-Strauss, 1982, p. 62). Ela localiza a hierarquia geracional tanto nas "regras de parentesco real" quanto nas relações entre os indivíduos e expressa a passagem da consanguinidade à cultura (Lévi-Strauss, 1982, p. 69-70). As estruturas elementares do parentesco mostram o lugar original do funcionamento das instâncias simbólicas na sociedade. Elas fornecem uma ordem desde o momento em que a sociedade "aparece como humana. Ora, é o que supóe igualmente o inconsciente tal como o descobrimos e manipulamos na análise" (Lacan, 1987, p. 45).

O exame do cogito cartesiano é suficiente para verificar que a dúvida metódica funda um sujeito sem qualidades. Nesse sentido estrito, é possível dizer que sua existência depende da razão (res cogitans), da dedução lógica e não do fato empírico de gozar de um corpo (res extensa). Entretanto, com Lévi-Strauss, Lacan mostra que o símbolo decompõe, organiza e dialetiza as relações de parentesco, os laços decorrentes da união de dois corpos sexuados. O Nome do pai formalizará, sob novas bases conceituais, a impossibilidade de separar a relação original do corpo sexuado com a linguagem.

\section{A metáfora paterna}

A formalização mais precisa da função paterna no primeiro ensino de Lacan foi a metáfora paterna. Ela implica a produção de um sentido novo por meio da substituição de um significante (desejo da mãe) por outro (Nome do pai), ao qual se vincula um valor fálico: Nome do pai $(\mathrm{A} / \Phi)$ (Lacan, 1999, p. 202). 
Para Freud, a sublimação é um processo referido à libido investida no objeto e "consiste no fato de a pulsão se dirigir no sentido de uma finalidade diferente e afastada da [...] satisfação sexual" (1977a, p. 111). Trata-se da transformação da satisfação pulsional em um valor positivo e não ao seu recalque. Se a intervenção paterna contribui para o recalque ao promover a renúncia à satisfação pulsional e a identificação, ela também opera no sentido de provocar uma transformação no âmbito da própria pulsão. Diferentemente do recalque, a sublimação não exige renúncia ao gozo. Ela propicia uma mudança relativa ao gozo. Produz uma outra forma de satisfação no lugar do valor sexual obtido. Na operação do pai, está em jogo a substituição do valor de uso da criança pela mãe por um outro tipo de valor, simbólico. Essa operação é condição de inserção da criança na rede simbólica das trocas. $\mathrm{O}$ falo simbólico $(\Phi)$ é a medida da passagem do lugar previamente "simbolizado pela operação da ausência da mãe" (Lacan, 1998, p. 563) ao significante do Nome do pai como significado dessa ausência enigmática. O Nome do pai sustenta a ordem significante, e o falo é o significante que, por retroação, reúne todos os significados sob a égide do desejo. Interpretado miticamente no campo da linguagem, o desejo recobre a ausência de saber sobre o sexo.

A consequência teórica mais importante da metáfora paterna foi a introdução do desejo no campo do Outro, ponto de partida para o segundo ensino de Lacan. Inscrever o falo $(\Phi)$ em A é dizer que ali há uma hiância. É afirmar que a operação do recalque funciona também a serviço do princípio do prazer. O desejo é o resíduo da operação lógica do recalque que prova que o sujeito é marcado pelo significante mestre no mesmo lugar em que é habitado pelo desejo do Outro. O sintoma é a manifestação da face de objeto que impede reduzir o sujeito à cadeia significante $S_{1}-S_{2}$, "penso, sou". A inclusão da significação fálica (ou da sexualidade e do desejo) no campo do Outro torna impossível passar pelo código sem que o desejo se apresente enquanto objeto vazio de imagem, resto do encontro do sujeito com a linguagem (Miller, 1999a, p. 106-118). Isso esclarece por que a elaboração, por Lacan, do campo do Outro como código (A) não é sinônima de conceber o saber como um cosmo fechado. O Outro lacaniano equivale ao universo infinito $(\mathbf{A})$.

Quando o Outro foi definido como tesouro dos significantes, o Nome do pai era o significante da tradição que localizava o sujeito em relação às diferenças sexual e geracional, interditava a relação primária entre o sujeito e o objeto, e garantia a consistência da inserção do sujeito na cultura e na partilha dos sexos, identificando-o a uma significação fálica. Essa formalização do Outro e do Nome do pai está de acordo com o campo do saber constituído como infinito a partir do advento da ciência moderna. A operação metafórica 
feita pelo pai reinseria o aspecto sacro necessário à manutenção da relação do sujeito com a enunciação e garantia a impossibilidade da obtenção de um sujeito sem qualidades porque o definia como desejo de exceção. Nesse sentido, o Nome do pai era o nome do sujeito suposto saber a razão e a ordem dos corpos e das coisas. Assim, o campo do saber mantinha-se, até certo ponto, dependente da transmissão e dava lugar à dívida simbólica. No entanto, o advento da ciência condenou ao declínio o lugar do pai na Modernidade. Ele não está à altura de representar Deus a contento, portanto não pode mais responder pela função de interdição. Quanto mais a ciência se imiscui no mundo, quanto mais mostra seus efeitos progressivamente associados ao advento do capitalismo, mais desvela a precariedade da função metafórica do pai, porque o outro significante $\left(S_{2}\right)$ para o qual $S_{1}$ representa o sujeito é, cada vez mais, um significante caracterizado por um saber opaco em relação à verdade que o causa. Desde então, potencialmente, todo saber é um saber em questão. $O$ universo do discurso não pode mais ser considerado um cosmo fechado. Isso me permite afirmar que o matema é o modo como Lacan passou a escrever o universo infinito do discurso introduzido no mundo pelo advento do discurso da ciência moderna, cabendo agora ao desejo a responsabilidade de dar provas dessa hiância no plano psíquico (Lopes, 2007).

Se a ordem simbólica está articulada ao redor desse furo $(\mathbf{A})$, então S(A) pode ser considerado "um matema do Nome do pai" (Maleval, 2002, p. 91), cujo surgimento é secundário em relação à castração no Outro. Se "todo enunciado de autoridade possui como garantia única sua [própria] enunciação" porque nenhuma linguagem permite articular toda verdade, o Nome do pai é impronunciável tal como $S(\mathbf{A})$. Sem poder mais ser confundido com o patronímico, deve ser tomado em sua função de nome próprio, ou seja, pelo valor diferencial peculiar a todo significante. $\mathrm{O}$ nome próprio tem afinidade com a marca, com a designação direta do significante com o objeto, com a letra e com o traço unário. Implica uma identificação regressiva ao traço unário que funda o Outro a partir de uma operação de corte ${ }^{1}$ com a tradição (Lacan, 1961-1962, 10-1-1962).

\footnotetext{
O termo "corte" advém de corte epistemológico, um conceito fundamental no interior da epistemologia de Bachelard, que designa as rupturas ou as mudanças súbitas ocorridas na história da ciência que explicam por que "O passado de uma ciência atual não se confunde com essa mesma ciência no seu passado” (Canguilhem, 1977, p. 15). Privilegiar o corte para definir o advento do sujeito situa Lacan alinhado à tese bachelardiana de que o progresso científico progride por descontinuidade e não pela sucessão dos fatos. Essa lógica é a mesma usada por Freud ao definir a constituição subjetiva pela perda de uma parte da realidade (1924) ou ao conceituar a Spaltung do eu no processo de defesa em relação à castração materna (1940 [1938]).
} 


\section{O Nome do pai e a introdução do desejo no campo do Outro}

A introdução do desejo no campo do Outro produziu um deslocamento teórico que implicou duas vertentes para o Nome do pai: uma referente à formalização do Édipo pela metáfora paterna, responsável por excluir o gozo e indicar a série constitutiva do desejo; e outra relativa à nomeação, ou seja, à uma articulação particular, e não mais universal, do sujeito com o Outro primordial pelo complexo de castração. O Nome do pai tem função de escritura. Tem afinidade com o vínculo direto do significante com o objeto perdido (Lacan, 1961-1962, 10-1-1962). A função do nome próprio é a de inscrever, nomear a perda de realidade que funda a ordem simbólica por meio de uma marca sem qualidades. Por essa razão, ele conserva sua estrutura de uma língua para a outra. Mas o sujeito que resulta dessa operação não é isento de gozo porque, se o traço surge do objeto, ele retém algo desse objeto, sua unicidade. Isso esclarece porque o Nome do pai funciona como ponto de basta para a infinita remissão de um significante a outro pela máquina simbólica. Ele encarna o vínculo do significante com o objeto, implica a libido, o gozo original com o objeto. Ao reter algo do objeto, o significante, que se distingue por ser material sem ter substância, retém algo do gozo e, com isso, substancializa-se.

No primeiro ensino, Lacan formalizou o Édipo freudiano pelo Nome do pai quando o tomou como equivalente a um significante da tradição que localizaria o sujeito no laço social. O Nome do pai encontrava-se superposto ao simbólico excluindo o gozo com o objeto, sendo essa exclusão necessária à consistência da própria simbolização. Portanto, reinserir o Nome do pai implicava a reintrodução da dimensão alteritária da constituição subjetiva que havia sido recalcada e concernia ao funcionamento psíquico nos moldes do Outro como universal. Isso corresponde à reintrodução do recalcado que retorna por meio do supereu herdeiro do complexo de Édipo. No entanto, a inconsistência do Outro levou Lacan à conceituação do objeto $a$, fato que introduziu uma nova objeção da psicanálise ao discurso da ciência: a necessidade de se pensar que o sujeito do significante é um sujeito encarnado em um corpo. O sujeito reduzido ao puro significante, ponto de convergência entre a psicanálise e a ciência, é uma ilusão. É o que mostra a relação do desejo com a perversão. $\mathrm{O}$ perverso eleva o objeto de uso à dignidade de objeto de troca ao substituir o objeto (pênis) que falta à mãe por outro, em relação ao qual realiza um lucro ao atribuir-lhe a condição de fetiche. Isso contraria a apreensão da função do pai como Ser Supremo. Nesse sentido, homem e mulher não podem mais ser reduzidos a puros significantes. É preciso considerar como é que cada um recupera o gozo pulsional perdido na assunção desses lugares, isto é, quais as 
consequências psíquicas do complexo de castração. Para isso, Lacan repensa "a relação do significante com o que está fora da simbolização" e retifica a separação entre o campo do Outro e o gozo. Em decorrência, o Nome do pai precisará incluir algo relativo ao gozo. A promoção do conceito de objeto $a$ e a ênfase no fantasma $(\$ \diamond a)$ respondem a essa necessidade. Permanecer no gozo maciço situado fora do sistema simbólico impede pensar a relação entre o gozo e o Outro (Miller, 1999b, p. 93).

Lacan reelabora a falta de gozo como falta irredutível ao significante, não suplementável pelo simbólico e correlata à falta de saber sobre o sexo feminino. Essa é a estrutura do objeto $a$, que considera, no circuito pulsional, a recuperação do gozo ao qual o sujeito (macho ou fêmea) renunciou para constituir-se como tal. Considerar a libido expulsa do aparelho psíquico (irredutível à metáfora) implica a estrutura fantasmática e não só a trama edípica. Entre o plano da existência do sujeito e o do sentido da vida, entre o campo do ser e o campo do Outro, é preciso pensar o inconsciente como lugar da interseção entre a linguagem e o corpo. Lacan definia o inconsciente como discurso do Outro (campo da linguagem). Isso permitia que ele fosse decifrado. No entanto, há algo que não permite decifração. $O$ conceito de Nome do pai, o objeto $a$ e o fantasma provam que a constituição da subjetividade sempre mantém algo do imaginário infantil, impedindo que o sujeito possa ser reduzido ao sujeito sem qualidades.

O primeiro ensino de Lacan recompôs a estrutura subversiva da psicanálise freudiana em relação à cultura: o simbólico é anterior a qualquer experiência, e o pai é o eixo de toda constituição subjetiva, que se caracteriza pela produção de um sujeito mortificado que sonha com um gozo impossível de ser alcançado. Porém, a partir do Seminário 10, o pai não produz mais um sujeito desconectado do gozo porque ele próprio testemunha que o gozo é acessível em pequenos fragmentos. Isso só é possível se o sujeito do significante for substituído por um corpo vivo e o complexo de castração tiver primazia sobre o Édipo. Como Lacan operou esse deslocamento em relação à definição de sujeito?

O que está em jogo é a face do sujeito que a operação da Aufhebung não consegue abolir: a ligação $(\diamond)$ do sujeito $\left(\mathbf{\$}\right.$, correlato do par $S_{1}-S_{2}$ ) com sua face de gozo $(a)$. Portanto, no exercício da função de nomeação, o que se produz através do pai não é só um desejo normalizado pelos caminhos da lei, mas "o fato de que, na manifestação do seu desejo, o pai sabe a que [objeto] $a$ esse desejo se refere". O pai não é uma causa sui tal como Deus ou os mitos freudianos fazem crer, mas "o sujeito que foi longe o bastante na realização de seu desejo para reintegrá-lo no que há de irredutível na função de $a$ " (Lacan, 
2005, p. 365-366). Então, no lugar de excluir totalmente o gozo, o pai o localiza como possível em um objeto causa do desejo (a), ou seja, instaura o gozo como sendo parcial, fragmentado, marcado pela impossibilidade de ser desfrutado de modo pleno.

Para considerar a libido como objeto que repara a perda de vida em jogo na reprodução sexuada, Lacan precisou redefinir o conceito de Outro. A mortificação era uma necessidade lógica inerente à cadeia significante e à constituição subjetiva. Mas a introdução do desejo no Outro tornou necessária a consideração do Outro como um campo em que o vivo do sujeito é chamado à subjetividade porque questiona a relação da pulsão com a sexualidade. Como a sexualidade se presentifica no psiquismo se nenhuma pulsão é capaz de representar a função da reprodução? Se é no campo do Outro que o sujeito deve aprender o que fazer como homem ou mulher, como ele aprende, como resolve o problema da identificação se não há significante do sexo feminino? Lacan responde a essa questão, afirmando que o gozo da pulsão como pulsão parcial é o que orienta o sujeito (1988, p. 194-195). Trata-se de uma desmontagem do conceito freudiano de pulsão (Lacan, 1988, p. 153-189). Por oposição ao campo narcísico do amor, a pulsão implica uma satisfação obtida no contorno que denuncia a hiância e impede a reciprocidade. A pulsão se reduz a uma pura atividade gerenciada pela forma verbal reflexiva se fazer (sugar, defecar, ver...). O gozo pulsional é parcial e implica, de saída, tanto a presença de uma falta quanto o sujeito na posição de objeto, fazendose contornar, suturando uma falta com outra. A função do objeto $a$ demarca o vazio no qual a pulsão se satisfaz.

\section{O Nome do pai e o Outro como campo do vivo}

O Seminário 11 correlaciona o inconsciente estruturado pela linguagem $\left(S_{1}-S_{2}\right)$ ao inconsciente pulsional, homogêneo a uma zona erógena. Essa correlação introduz a lei do significante no domínio da causa e torna o sujeito equivalente à causa do desejo como algo que não se encaixa nessa lei $(\mathbf{\$} \diamond a)$. Por essa razão, o inconsciente é também repetição do fracasso da articulação significante. Isso dá um estatuto ético ao inconsciente em relação ao desejo. A ética em jogo é a do corte que constitui o circuito pulsional em que o desejo se realiza de um modo sempre inédito, mas sem se satisfazer. Essa visada do inconsciente depende da nova definição que Lacan (1988, p. 194) dá ao conceito de Outro como "campo desse vivo onde o sujeito tem que aparecer". Essa novidade promove o giro teórico de Lacan em relação à noção de gozo. No lugar do gozo impossível, excluído do circuito, advém o gozo 
normal ou parcial (Miller, 1999b). A reintrodução do vivo depende de um novo dimensionamento sobre a natureza do real que escapa ao simbólico e que permite pensar a pluralização dos nomes do pai. O simbólico não se reduz à transmissão de uma identificação válida para todos. Ele também cria, faz existir algo que não existia antes. Como efeito, a transferência não é pensada somente pela suposição de saber, pela decifração de algo que já estava lá. Ela também implica a presentificação do novo (Santos, 2005, p. 87). Não se trata de um abandono do inconsciente estrutural, mas da relativização do valor daquela abordagem à luz de outra perspectiva: a do inconsciente como pulsação temporal (Miller, 2004; Santos, 2002, p. 8). Lacan distingue a causa e a lei e afirma que, contrariamente à lei, a causa implica sempre algo de anticonceitual, o que situa o inconsciente como tropeço entre a causa e o que a afeta. $\mathrm{Na}$ descontinuidade, o inconsciente introduz o Um da fenda, do traço, da ruptura sujeito-objeto, e não o Um da unidade egoica (Lacan, 1988, p. 28-31).

Lacan (1998, p. 831-832) inicia uma revisão conceitual em relação à linguagem. Por um viés, a pulsão é o que advém da demanda $\left(S_{1}-S_{2}\right)$ quando o sujeito comparece como fading (desvanecimento) para surgir como objeto destacado (a) do campo do Outro. Mas, quando isso ocorre, a demanda também desaparece, uma vez que ela requer uma dialética. Quando a demanda desaparece, a pulsão é traço unário, pura diferença, corte que presentifica a distinção entre a pulsão e a função orgânica que ela habita. Esse corte se "beneficia do traço anatômico de uma margem ou uma borda". As reversóes pelas quais a pulsão se articula com sua fonte e com o objeto revelam o artifício gramatical da pulsão e isolam a zona erógena em relação ao metabolismo da função à qual ela pertence. $\mathrm{O}$ "traço do corte" se evidencia nos objetos que a teoria psicanalítica isola e descreve: mamilo, cíbalo, falo, olhar, voz e nada. A presentificação desses objetos não permite que a psicanálise tome o corpo cartesianamente, porque eles correspondem a uma parte de libido perdida, destacada, separada do corpo em decorrência da sexuação. A correlação entre $S_{1} S_{2}$ e $\mathbf{\$} \diamond a$ identifica a nova topologia do inconsciente estruturado como linguagem que dá conta da constituição do sujeito como sexuado. $\mathrm{O}$ fantasma não é uma gramática aplicada aos objetos parciais. Ele implica também o complexo de castração, agora sob o modo da separação.

A operação de alienação mostra que o sujeito só pode ser reconhecido no campo do Outro, razão pela qual não pode ser pensado como consciência de si. Entretanto, sem poder nomear totalmente o sujeito, o Outro produz um resto: o sujeito barrado $(\mathbf{S})$. Isso quer dizer que à identificação, preço pago pelo sujeito para encontrar-se no Outro pela via do sentido, corresponde 
a perda de uma parte da realidade que não se dobra ao sentido, o objeto a. Trata-se da unificação dos conceitos de identificação e recalque (Miller, 1999b, p. 93) ou do fading inerente à identificação.

A operação de separação surge do recobrimento das duas faltas: a encontrada no Outro sob a forma de desejo e que suscita a questão "o que queres?", e a outra indicada pelo fato de o sujeito responder a essa pergunta com a sua própria falta. $\mathrm{O}$ apagamento do sujeito faz com que ele compareça como objeto (que suplementaria a castração localizada no Outro) e pague pelo logro narcísico no qual o vivo sexuado é induzido à completude. A estrutura faltosa do Outro, ou sua inconsistência, deve ser tomada em relação à diferença sexual e é o lugar em que o objeto que causa o desejo comparece como perdido. $\mathrm{O}$ efeito é uma fixação no Outro por meio do fantasma.

Nesse ponto, uma questão se impõe: com a teoria da nomeação, estaria em curso a redução da função paterna ao simples ato de nomear? (Lacan, 1988, p. 224) Não, uma vez que a atividade de etiquetar objetos deixa escapar a essência da linguagem porque não põe em questão o desejo de quem executa a tarefa, não considera sua posição como sexuada. Se o essencial da pulsão na alienação é o sentido do sexo, o objeto $a$ é o que serve de suporte à nomeação. Ele estanca a vacilação do ser (Lacan, 1988, p. 243) porque não responde à lei de representar o sujeito para outro significante. Portanto, ao incluir a causa, o pai recoloca no jogo da constituição subjetiva o valor de uso do objeto como objeto de gozo. Lacan reescreve o pai da metáfora paterna por meio de uma nova figura do pai: "aquele que sabe que o objeto $a$ é irredutível ao símbolo". Portanto, ele não seria enganado pela metáfora paterna porque não acreditaria que ela pudesse realizar uma simbolização integral. Assim, saberia "ligar o desejo ao objeto pequeno $a$ como sua causa" (Miller, 2005, p. 68).

A alienação e a separação mostram a íntima articulação entre o simbólico e o gozo. Inserem-se no próprio funcionamento significante e mostram que há gozo no Outro (Miller, 1999b). Coordenadas ao "abre e fecha" das zonas erógenas, superam a metáfora paterna e a metonímia do objeto como objeto do desejo, abrem o caminho para a abordagem da linguagem como produtora de mais de gozar e para um novo paradigma relativo ao gozo, o do gozo discursivo.

\section{$6 \mathrm{O}$ Nome do pai e o objeto a como função lógica}

O caminho conceitual até a noção de discurso é precedido pela apresentação, no Seminário 16, do objeto a como função lógica, consistência que responde à inconsistência do Outro (Miller, 2007). Lacan faz uma reflexão sobre a perda 
como efeito do discurso e sobre o Nome do pai como traço unário. O objeto a é o nome da perda correspondente à inscrição do traço unário. Isso quer dizer que aquilo que comparece como resto da operação significante está, na verdade, articulado à atividade do sistema simbólico. O que comparece como Um se relaciona necessariamente com a perda. Todo Um é sempre $1+$ a, traço unário + efeito da perda estrutural. A abordagem lógica permite a Lacan situar o pai como um "número que se encontra no princípio regulador de uma cadeia cujo ponto de partida é um vazio" (Maleval, 2002, p. 106). O unário opera com o zero. Isso quer dizer que o princípio de ordenação da cadeia é o próprio corte. O real é ordenado pelo recorte simbólico. O Um que pode ser contabilizado implica a pura diferença, porque é nela que ele se funda. Lacan (1992, p. 117) demonstra que à radicalização da autonomia do significante corresponde necessariamente a produção de um mais de gozar que transforma em ganho o que se produz como perda no interior do sistema simbólico. Isso permite deslocar o gozo para o campo do inconsciente e situar a castração como estrutural e não mais como resultado da operação paterna. A separação entre o significante e o gozo encontra seu termo porque o significante passa a regular o gozo por meio de um aparelho, o discurso. Essa regulação define o discurso como uma interpretação do real, uma submissão do real à lei do significante unário (e não "unificador").

\section{O Nome do pai e o Outro discursivo}

A noção de discurso trouxe a ideia de que a relação entre o significante e o gozo é primitiva e originária porque todo discurso é movido por uma causa (Miller, 1999b, p. 95). Essa é a razão pela qual Lacan faz a passagem do significante aos discursos. Ao axioma "o significante é o que representa o sujeito para um outro significante", Lacan acrescentará a definição de que o significante é aparelho de gozo. Mas isso significa abolir a "autonomia" do simbólico? Em O seminário sobre "A carta roubada" (1998, p. 13-66), Lacan demonstrou a existência de uma lógica autônoma dos significantes (a ordem simbólica) que funcionava independentemente dos corpos, chegando, de certo modo, a transcendê-los. Nesse âmbito, a lei que dirige e sujeita os discursos e os corpos é uma lei sólida. Com a conexão do significante com o gozo através do objeto $a$ e do mais de gozar, Lacan promove um retorno ao corpo (Miller, 1999b). Faz da linguagem um veículo de gozo. Entretanto, devido ao declínio da primazia do simbólico na cultura, esse registro não seria mais tomado como "a" ordem simbólica, mas como "uma" ordem simbólica. Estaríamos no nível de várias ordens simbólicas, e isso implicaria mais do que a unicidade da lei. Implicaria uma ordenação. 
Será que isso corresponderia, então, a pensar a lei como um arranjo imaginário de elementos? Do ponto de vista da orientação de uma análise, isso seria possível? Seria essa uma formulação coerente com a tarefa da psicanálise de reintroduzir o Nome do pai na consideração científica? (Lacan, 1998, p. 889). Quando a hegemonia simbólica declina, quais parâmetros sustentam a interpretação analítica? Despido dos ideais coletivizantes, como manter o caráter subversivo da função paterna? Onde ancorar a dessimetria? A que problema Lacan responde com a conexão do significante com o gozo?

Freud (1977b) isolou um tipo de economia além do princípio do prazer que comparecia como um paradoxo em relação ao espírito moderno, pois se presentificava como uma tendência oposta ao progresso, à adaptação, ao bemestar e até à própria vida do sujeito. A questão deixada por Freud exigia saber como a insistência pulsional, produtora de diferenças, transformava-se em obstáculo à análise ao apresentar-se sob a forma da repetição e como é possível tratar disso que se repete. Nesse sentido, o passo teórico dado por Lacan em relação ao ponto de detenção de Freud foi a positivação da diferença entre o prazer da satisfação exigida pelo circuito pulsional e a satisfação realmente usufruída. Lacan se orientou pela angústia, afeto que indica que, no mesmo ponto onde algo do corpo foi perdido, destacado, algo do desejo se encontra em vias de advir como mais de gozar. É que o traço que modela a perda em jogo na constituição subjetiva é também o que permite engendrar a função do vazio como causa e mover o aparelho psíquico na direção do que não é ainda. A estrutura tem afinidade com a forma, com o traço, cuja função de corte contorna, enforma um vazio potencialmente criador. Nesse sentido, o inconsciente não presentifica somente a repetição do gozo mortificado $\left(S_{1}-S_{2}\right)$, perdido, mas é também causa do gozo recuperado $(\$ \diamond$ a). Assim, o que era obstáculo (a repetição) é retomado como atividade básica do sistema, como repetição de gozo, criação de mais de gozar.

O Outro ( $)$ passa a ser tratado como campo pulsional lógico, cujo circuito de trabalho é impulsionado pelo seu não fechamento. O objeto $a$, por sua vez, é o que é reincluído como mais de gozar, suplência à inconsistência do próprio sistema. A noção de estrutura implica o vazio como causa (a castração) e a repetição articulada ao gozo com o vazio. Isso significa que é impossível ao significante ser sem qualidades e que a repetição inconsciente não produz apenas gozo perdido ou falta de gozo, mas é causa de um gozo recuperado sob a forma de um lucro. O conceito de mais de gozar marca o que excede ao sistema a partir de uma nova perspectiva: a diferença que não se inseria no circuito das trocas é positivada e reintegrada como objeto novo a ser consumido. $\mathrm{O}$ objeto perdido e o mais de gozar devem ser pensados topologicamente. O objeto 
$a$ é definido de modo lógico e se torna um elemento calculável. Isso traz consequências para a direção do tratamento porque localiza a castração como o real em jogo e retira de cena toda a abordagem do gozo como comportando uma possibilidade de transgressão (Lacan, 2006).

Com a noção de discurso, o gozo não está mais fora do sistema, mas participa dele porque o significante é causa do gozo. Portanto, a repetição não visa ao encontro com o objeto perdido, mas o desperdício porque é gozo com a falta desse objeto. No discurso, a repetição é repetição de gozo e o mais de gozar é o lucro, o bônus que se obtém quando se goza com a falta. Santos (2001, p. 231) define o discurso como "uma forma de vincular o sujeito e suas pulsões, sempre parciais, com o Outro". Essa definição está estreitamente ligada à tese freudiana (1977c) que articula a psicologia do sujeito à psicologia do grupo e é correlativa à defendida por Miller, quando separa as categorias de sujeito e indivíduo porque o primeiro é inseparável da civilização (Miller \& Milner, 2006, p. 30).

No Seminário 17, Lacan conceituou quatro discursos caracterizados por uma sucessão e uma combinatória de letras que sempre inclui uma impossibilidade interna. Ao incidirem sobre o corpo, os significantes engendram um saber acerca da verdade que o causa: a ausência de relação prévia entre os significantes. Assim, a hiância estrutural ressurge como mais de gozar.

Lacan parte do discurso do mestre. Todos os outros discursos (histérica, universitário e psicanalista) são formados a partir desse, girando os elementos na proporção de um quarto de volta. No discurso do mestre moderno, um sujeito $\left(S_{1}\right)$ se localiza em uma posição exterior ao campo do Outro, campo do saber $\left(\mathrm{S}_{2}\right)$ inconsistente. Para que se encadeie como enunciado, o significante $S_{1}$ deve intervir sobre a bateria de significantes $\left(S_{2}\right)$ que, justamente por serem prévios e se organizarem como saber, não constituem uma bateria dispersa. Ao intervir sobre $S_{2}, S_{1}$ passa a representar o sujeito como mortificado (\$ $)$ (Lacan, 1992, p. 11-12). O nome próprio comanda o processo identificatório enquanto agente do discurso e se torna, então, "o significante em nome de quem eu falo [...], o índice da dívida [do sujeito] com o fundador" (Santos, 2004 b, p. 7). Quando $S_{1}$ intervém sobre $S_{2}$, ele produz um sujeito dividido $(\mathbf{S})$ e um resto $(a)$ que se perde nessa operação. O discurso do mestre grafa simultaneamente o que se perde com a mortificação do sujeito quando o significante mestre incide sobre a bateria de significantes e o que se consegue recuperar como mais de gozar.

$$
\begin{gathered}
\underline{\mathrm{S}}_{\underline{1}^{-}} \rightarrow \underline{\mathrm{S}}_{2} \\
\mathbf{S}(\diamond) a
\end{gathered}
$$


Se a castração é primordialmente simbólica, se está na linguagem, se é uma "operação real introduzida pela incidência do significante [...] na relação do sexo" (Lacan, 1992, p. 121), a função do pai agora é a de dar provas da castração à qual ele próprio está submetido. $\mathrm{O}$ mito do assassinato do pai mascarava a sua castração. E é por ser castrado que o pai sabe a que objeto $a$ o seu desejo se refere: uma mulher. $\mathrm{O}$ objeto a substitui a mulher que o homem deseja (Lacan, 1992, p. 146). O Nome do pai implica o gozo que dá um sentido sexual ao real em jogo. Dos mitos freudianos sobre o pai à estrutura da linguagem, descortina-se o operador estrutural da constituição subjetiva: a castração e não o Édipo. A castração não é uma fantasia e o pai só opera secundariamente, como metáfora (Lacan, 1992, p. 105). Enquanto nomeação, oferece um sentido sexual à castração estrutural experimentada na linguagem. Assim, reitera a existência de uma estrutura homogênea entre a linguagem e a sexualidade. Não há acesso à posição sexuada senão pela via do significante em sua função de nomeação, de extração de mais de gozar a partir de uma perda inevitável. O verdadeiro trauma que a sexualidade impõe ao humano é a submissão do desejo a um objeto caracterizado por uma escolha contingente, sempre incompreensível. O pai é uma função simbólica secundária que se escreve pelo testemunho da sua fraqueza diante do objeto causa de seu desejo. A função paterna é efeito (e não causa) da castração instaurada pela linguagem.

A distinção entre a castração estrutural e seu comparecimento fantasmático, como interdição efetuada pelo pai, permite a Lacan formalizar o Nome do pai de um modo novo sem perder a sua eficácia simbólica. A função de nomeação ligada ao Nome do pai localiza a eficácia da nomeação na palavra do pai, no fato de que "alguém se levanta para responder" (Porge, 1998, p. 147). Para além do pai, há um homem; para além do sujeito, há o ser falante sexuado.

A operação paterna identificada ao ideal se desloca cada vez mais na direção de localizar o corpo como sexuado e o gozo ligado ao modo como a pulsão se articula à linguagem. Isso não seria possível sem a definição do Outro como campo em que o vivo do sujeito é chamado à subjetividade (1988, p. 194). Como efeito, a função paterna passa também à tarefa de despertar e dar consistência ao corpo mortificado pela alienação ao significante unário. Se a reprodução sexuada exige uma "libra de carne" , a função paterna transmite a castração como um saber sobre a causa sexual. Para que um homem transmita a seu filho um saber sobre o corpo como sexuado, e não apenas a identificação

Expressão usada por Lacan, em $A$ direção do tratamento e os princípios do seu poder, a propósito da função do significante fálico em relação à constituição do desejo (1998, p. 636). 
a um ideal, ele precisa ter alguma relação com o que causa o seu desejo. O Nome do pai restitui ao sujeito a tragédia própria à existência humana: o fato de que todo sujeito tem um corpo destinado à morte e um sexo que escreve no corpo esse destino.

$\mathrm{Na}$ formalização dos mitos freudianos pelo estruturalismo antropológico e linguístico, a relação do significante com o gozo produziu dois efeitos: a separação entre o campo do Outro (A) (do supereu herdeiro do complexo de Édipo) e o do gozo (a), e a suposição de que homem e mulher jogavam o mesmo jogo no plano identificatório, ou melhor, de que eles não passavam de significantes organizados por oposição. Esse ponto não sofreu modificações quando Lacan teorizou a fórmula da fantasia. A topologia do Outro consistente (A) permitiu reduzir o sujeito a uma articulação significante $\left(S_{1}-S_{2}\right)$. Mas essa redução produzia um resto absoluto localizado, no Seminário 7 , como fora do sistema. A linguística desvelou o Outro como campo propício à deriva porque, diante de uma articulação significante qualquer, é sempre possível perguntar "mas o que isso quer dizer?”. A essa infinitização, o Nome do pai respondeu primeiramente com uma metáfora fálica e, logo depois, com o traço unário. Mas foi a conceituação do objeto $a$ que permitiu localizar o Outro como lugar do obstáculo. O Outro não pode ser um conjunto de significantes porque é impossível reunir todos os significantes em um mesmo conjunto (Lacan, 2006, p. 60). $O S_{1}$ não requer mais um ideal separado do objeto $a$ como seu complemento, mas apenas um outro significante $\left(\mathrm{S}_{2}\right)$. $\mathrm{O}$ passo que Lacan dá entre o texto $A$ ciência e a verdade e o Seminário 16 é o de deslocar a ênfase na divisão do sujeito em prol de privilegiar a manifestação do gozo em sua função estrutural como mais de gozar. Isso permite dizer que o que é da ordem do saber não se funda no Um marcado pela identificação primária ao ideal do eu (\$), mas no discurso do mestre. $\mathrm{O} \mathrm{S}_{1}$ é histórico e relativo a um $\mathrm{S}_{2}$. Por isso, ele é, ao mesmo tempo, fundador e multiplicador. Se o saber não pode mais conter a si mesmo, então, o Outro é apenas um campo lógico. Não é um campo fechado tanto quanto o universo da ciência não é finito. Como consequência, o sujeito é o efeito de uma conexão significante que o priva de um saber fechado sobre si mesmo. O conjunto de significantes do sujeito não contém o próprio sujeito, não é um conjunto fechado. O que, então, o sujeito encontra no campo do Outro? Apenas sua topologia subversiva em relação à topologia do sujeito da ciência. Só há sujeito como efeito de um dizer, de um recorte simbólico. Por isso, ele é sempre inédito. Seu estatuto é o de uma interpretação. $\mathrm{O}$ sujeito depende de outrem uma vez que não tem nenhuma relação direta com a verdade, pois o real é impossível.

O que o Nome do pai introduz pela vertente da nomeação é que não há saber e tampouco sujeito fora do dizer de alguém. Portanto, enquanto algo que nomeia, 
o significante não pode se escrever no campo do Outro porque a nomeação padece do gozo de um sujeito na sua relação particular com um objeto causa. A nomeação não é um $S_{1}$ puro, mas um $S_{1}$ ao qual se agrega um mais de gozar. Então, o sujeito é $1+a$ e não um sujeito sem qualidades, um homem universal reduzido à qualidade zero e, por isso mesmo, capaz de fazer parte das estatísticas e das avaliações de massa. Quando a nomeação entra no jogo, ela produz o Um $(1+a)$ e não o zero (Lacan, 2006, cap. 8).

Freud reinseriu a realidade psíquica no campo da ciência como o que faz obstáculo ao alcance do ideal da ciência e, com isso, criou um saber novo. A psicanálise nasceu do movimento de expansão da razão científica sobre o domínio da subjetividade uma vez que, estruturalmente, todos os homens são devotados à ilusão (Lopes, 2007). Lacan formalizou a realidade psíquica com o conceito de Nome do pai alinhado à proposta iluminista de despir o campo do saber das concepções imaginárias deixadas na psicanálise pelos mitos freudianos. Mas esse alinhamento nunca foi sinônimo de tornar a psicanálise cúmplice do ideal da ciência de reduzir toda forma de autoridade ao semblante e produzir um sujeito sem qualidades. Pelo contrário, é nesse, mesmo ponto que a psicanálise visa a retificar a ciência.

Lacan retomou a via freudiana resgatando o valor da razão científica e a potência da interpretação para mostrar que a via da razão não se opõe à da interpretação desde que a razão se oriente pela castração. A castração é, então, a redução de todas as medidas. Ela é a medida mínima, a regulação da qual não se pode abrir mão. A nomeação não é um semblante porque inclui o gozo relativo ao recorte do simbólico feito por um sujeito, inclui a castração. É enquanto reintrodução da causa como sexual que compreendo a reintrodução do Nome do pai na consideração científica e como tarefa da psicanálise, no segundo ensino de Lacan.

\section{Referências}

Canguilhem, G. (1977). Ideologia e racionalidade nas ciências da vida. Lisboa: Edições 70.

Freud, S. (1977a). Sobre o narcisismo: uma introdução. Edição standard das obras psicológicas completas de Sigmund Freud (v. 14, p. 83-119). Rio de Janeiro: Imago (texto original publicado em 1914).

Freud, S. (1977b). Além do princípio do prazer. Edição standard das obras psicológicas completas de Sigmund Freud (v. 18, p. 13-85). Rio de Janeiro: Imago (texto original publicado em 1920). 
Freud, S. (1977c). Psicologia de grupo e análise do ego. Edição standard das obras psicológicas completas de Sigmund Freud (v. 18, p. 89-179). Rio de Janeiro: Imago (texto original publicado em 1921).

Lacan, J. (1961-1962). O seminário, livro 9: a identificação. Aula de 10 jan. 1962. Inédito.

Lacan, J. (1987). O seminário, livro 2: o eu na teoria de Freud e na técnica da psicanálise (1954-1955). Rio de Janeiro: Jorge Zahar.

Lacan, J. (1988). O seminário, livro 11: os quatro conceitos fundamentais da psicanálise (1964). Rio de Janeiro: Jorge Zahar.

Lacan, J. (1992). O seminário, livro 17: o avesso da psicanálise (1969-1970). Rio de Janeiro: Jorge Zahar.

Lacan, J. (1998). Escritos. Rio de Janeiro: Jorge Zahar.

Lacan, J. (1999). O seminário, livro 5: as formaçôes do inconsciente (19571958). Rio de Janeiro: Jorge Zahar.

Lacan, J. (2005). O seminário, livro 10: a anguistia (1962-1963). Rio de Janeiro: Jorge Zahar.

Lacan, J. (2006). Le séminaire, livre 16: D’un Autre à l'autre (1968-1969). Paris: Seuil.

Lévi-Strauss, C. (1982). As estruturas elementares do parentesco. Rio de Janeiro: Vozes.

Lopes, R.G. (2007). O desejo do analista e o discurso do inconsciente. Tese de doutorado não publicada, Universidade Federal do Rio de Janeiro, Curso de Pós-graduação em Teoria Psicanalítica, Instituto de Psicologia, Rio de Janeiro.

Lopes, R.G. (2008) Quem é o sujeito da psicanálise?. Tempo psicanalítico, 40 (2), 249-272.

Maleval, J.-C. (2002). La forclusión del Nombre del Padre. Buenos Aires: Paidós.

Miller, J.-A. (1999a). Perspectivas do Seminário 5 de Lacan: as formaçōes do inconsciente. Rio de Janeiro: Jorge Zahar. 
Miller, J.-A. (1999b). Os seis paradigmas do gozo. Opção Lacaniana, 26-27, 87-105.

Miller, J.-A. (2004). O último ensino de Lacan (2002). Opção Lacaniana, 35, 6-24.

Miller, J.-A. (2005). Introdução à leitura do Seminário da Angústia, de Lacan (2004). Opção Lacaniana, 43, 7-81.

Miller, J.-A. (2007). Uma leitura do Seminário, livro 16: de um Outro ao outro (2005/2006). Opção Lacaniana, 48, 9-42.

Miller, J.-A. \& Milner, J.-C. (2006). Você quer mesmo ser avaliado? Barueri: Manole.

Milner, J.-C. (1996). A obra clara: Lacan, a Ciência, a Filosofia. Rio de Janeiro: Jorge Zahar.

Porge, E. (1998). Os Nomes-do-Pai em Jacques Lacan. Rio de Janeiro: Cia. de Freud.

Santos, T. C. (2002). Paradigmas do último ensino de Lacan. Rio de Janeiro: Sephora.

Santos, T. C. (2005). Sinthoma: corpo e laço social. Rio de Janeiro: Sephora. 